\title{
Suppression of hepatocyte growth factor activator inhibitor-1 leads to a more aggressive phenotype of prostate cancer cells in vitro
}

\author{
ANDREW J. SANDERS ${ }^{1}$, CHRISTIAN PARR $^{1}$, MALCOLM D. MASON $^{2}$ and WEN G. JIANG ${ }^{1}$ \\ ${ }^{1}$ Metastasis and Angiogenesis Research Group and ${ }^{2}$ Department of Clinical Oncology, \\ Cardiff University School of Medicine, Cardiff, UK
}

Received May 25, 2007; Accepted July 9, 2007

\begin{abstract}
The hepatocyte growth factor (HGF) pathway has been well documented as playing a vital role in the progression and development of many different types of human cancers; as such this pathway is usually tightly regulated. In cancer cells, the regulation of this pathway has been shown to be disrupted, allowing an increase in activation of pro-HGF to active HGF. There are a number of molecules capable of activating pro-HGF, such as matriptase-1, a type II transmembrane serine protease, or hepatocyte growth factor activator, and in turn, these are also subject to regulation. In the current study we examined the importance of hepatocyte growth factor activator inhibitor-1 (HAI-1) which is known to inhibit a number of HGF-activating molecules. We reduced the expression of this molecule in both PC-3 and DU-145 cell lines using hammerhead ribozyme technology, and we examined various important characteristics associated with cancer progression and development in vitro. Prostate cancer cells, after loss of HAI-1, had a significantly increased in vitro invasiveness together with an increase in cellular motility. Notably, loss of HAI-1 resulted in a slower rate of cell growth over a prolonged period (5 days). This in vitro evidence collectively suggests that the suppression of HAI-1 expression gives rise to a more aggressive cancer cell phenotype. This implies that therapies inducing the overexpression of HAI-1 or delivering an exogenous source of HAI-1 protein may hold potential as a treatment to slow the progression of prostate cancer.
\end{abstract}

\section{Introduction}

Hepatocyte growth factor (HGF) was originally identified in 1984 as a new factor present in the serum of partially

Correspondence to: Dr Andrew J. Sanders, Metastasis and Angiogenesis Research Group, Cardiff University School of Medicine, Heath Park, Cardiff CF14 4XN, UK

E-mail: sandersaj1@cardiff.ac.uk

Key words: hepatocyte growth factor, hepatocyte growth factor activator inhibitor-1, cell invasion, prostate cancer hepatectomized rats and in the lysate of rat platelets which was capable of stimulating DNA synthesis and promoting hepatocyte growth (1-3). Since its identification, HGF has become a molecule of great interest due to its links with cancer. Hepatocyte growth factor/scatter factor (HGF/SF) has been shown to induce angiogenesis in vivo (4), to stimulate proliferation, migration and morphogenesis in endometrial epithelial cells (5) and to induce or promote invasiveness in a number of different carcinoma cell lines (6). All of these processes are important in cancer progression, and targeting of the $\mathrm{HGF} / \mathrm{SF}$ molecule or its receptor c-MET has been associated with a less aggressive cancer cell $(7,8)$.

In order for the inactive pro-HGF to exert these effects, it must first be activated via proteolytic cleavage from inactive single-chain pro-HGF to the active heterodimer $(9,10)$. $\mathrm{HGF} / \mathrm{SF}$ can be processed by proteases such as hepatocyte growth factor activator (HGFA) $(11,12)$ and matriptase-1 (13), which are in turn regulated and inhibited by other molecules. This processing of $\mathrm{HGF} / \mathrm{SF}$ is a key regulatory step and is often imbalanced in various cancers.

Two potent inhibitors of HGFA were identified from the conditioned medium of the MKN45 stomach carcinoma cell line and were termed hepatocyte growth factor activator inhibitor type 1 and type 2 (HAI-1 and HAI-2). HAI-1 and HAI-2 are Kunitz-type inhibitors and both contain two Kunitz-type inhibitory domains and a transmembrane domain at the C-terminus end. Although HAI-1 and HAI-2 are structurally similar molecules, they differ in a number of regions. HAI-1 contains a low-density lipoprotein receptorlike domain between its two Kunitz domains which is not present in the HAI-2 molecule $(14,15)$. Similar findings have been seen following cloning and characterisation of the HAI-1 and HAI-2 genes, which were mapped to chromosome $15 \mathrm{q} 15$ and $19 q 13.11$ respectively (16). Since its initial discovery as a potent HGFA inhibitor, HAI-1 has demonstrated the ability to inhibit a number of other serine proteases including hepsin (17), trypsin and matriptase-1, where the specificity of this inhibitor is largely due to Kunitz domain 1 (18). However, HAI-1, as well as inhibiting matriptase-1, may also play a role in the activation of matriptase- 1 as co-expression of HAI-1 mutated in the low-density lipoprotein receptor class A domain prevented matriptase- 1 activation from occurring (19). 
HAI-1 expression has been shown to be altered in regenerating and injured tissues $(20,21)$. Together with its links to the HGF pathway, this suggests that this molecule is normally involved in the process of tissue regeneration and repair. However the key role of HAI-1 in the HGF pathway and its inhibitory effects on enzymes associated with cancer progression such as matriptase- 1 and hepsin, suggest that this molecule is likely to play a role in regulating cancer progression. The aim of this study was to examine the effects of reducing the expression of HAI-1 in two prostate cancer cell lines, PC-3 and DU-145. Reduction of HAI-1 expression was accomplished by using a hammerhead ribozyme transgene which specifically targeted and cleaved the HAI-1 messenger RNA. This transgene was then transfected into the PC-3 and DU-145 cell lines. Once knockdown of HAI-1 expression was confirmed, a number of in vitro functional assays were used to examine the cellular properties linked with key stages in cancer development and progression.

\section{Materials and methods}

Cell lines and culture conditions. PC-3 and DU-145 prostate cancer cell lines were purchased from the American Type Culture Collection (ATCC, Rockville, MD, USA). Cells were maintained in Dubecco's modified Eagle's medium (DMEM) (PAA Laboratories Ltd., Somerset, UK) supplemented with penicillin, streptomycin and $10 \%$ foetal calf serum (PAA Laboratories Ltd.). Cells were incubated at $37^{\circ} \mathrm{C}$ in $5 \% \mathrm{CO}_{2}$ and $95 \%$ humidity.

Generation of HAI-1-suppressed prostate cancer cell lines. PC-3 and DU-145 cell lines demonstrating suppressed HAI-1 levels were generated using a hammerhead ribozyme transgene system. This system was previously employed and reported by our group $(7,22,23)$. In brief, ribozyme transgenes that specifically recognize and cleave HAI-1 mRNA were designed based on the predicted secondary mRNA structure as previously reported (23). The ribozymes were designed as sense/antisense strands (Table I) and were combined using touchdown PCR. Following this, the transgenes were cloned into the pEF6/V5-His-TOPO vector and amplified in Escherichia coli. The plasmids were then subsequently extracted, purified, verified for correct size and correct sequence orientation and electroporated into both PC-3 and DU-145 prostate cancer cell lines. Insertion of the ribozyme transgene into these cells gave rise to the PC- $3^{\mathrm{HAI}-1 \mathrm{KO}}$ and DU-145 ${ }^{\text {HAI-1 KO }}$ cell types respectively. In addition, a pEF6 control plasmid (no ribozyme sequence) was also electroporated into wild-type cells to give rise to the PC- $3^{\mathrm{PEF} 6}$ and DU-145 $5^{\mathrm{PEF} 6}$ controls and used in comparison to the knockout cells in the functional assays.

RNA extraction and cDNA synthesis. RNA was extracted from cells cultured in $25 \mathrm{~cm}^{2}$ tissue culture flasks to confluency using the ABgene Total RNA Isolation Reagent (Advanced Biotechnologies Ltd., Surrey, UK). Following extraction, RNA concentration was determined using a UV spectrophotometer (WPA UV 1101, Biotech Photometer, Cambridge, UK) and normalised to $200 \mathrm{ng}$ of RNA for use in cDNA synthesis using an Enhanced Avian RT-PCR-100 kit with anchored oligo(dt) primers (Sigma, Dorset, UK). Following reverse transcription, cDNA quality was checked using B-actin (Table I) before specific probing of HAI-1 expression using HAI-1-specific primers. PCR was carried out using a T-CY thermocycler (Creacon Technologies Ltd, The Netherlands) and REDTaq ${ }^{\circledR}$ ReadyMix $^{\mathrm{TM}}$ PCR reaction mix (Sigma). PCR conditions were as follows: a 1-min denaturation step at $94^{\circ} \mathrm{C}$, a 2 -min annealing step at $55^{\circ} \mathrm{C}$, and a 3-min extension step at $72^{\circ} \mathrm{C}$. Extension was conducted over 38 cycles. PCR products were loaded onto a $0.8 \%$ agarose gel and electrophoretically separated before being stained with ethidium bromide and visualised under UV light. All PCR primers used were designed using Beacon Designer (Palo Alto, CA, USA) and were synthesised by Invitrogen (Paisley, UK).

SDS-PAGE and Western blotting. Cells were grown to confluence in a $75 \mathrm{~cm}^{2}$ tissue culture flask before being detached using a cell scraper and pelleted. The cell pellet was then lysed in HCMF buffer plus $0.5 \%$ SDS, $1 \%$ Triton $\mathrm{X}-100,2 \mathrm{mM} \mathrm{CaCl}{ }_{2}, 100 \mu \mathrm{g} / \mathrm{ml}$ phenylmethylsulfonyl fluoride, $1 \mathrm{mg} / \mathrm{ml}$ leupeptin, $1 \mathrm{mg} / \mathrm{ml}$ aprotinin, and $10 \mathrm{mM}$ sodium orthovanadate on a rotor wheel for $1 \mathrm{~h}$ before being spun at $13,000 \mathrm{x} g$ for $15 \mathrm{~min}$ to remove insolubles. The lysed protein was then quantified using the Bio-Rad DC Protein Assay kit (Bio-Rad Laboratories, CA, USA). The protein samples were then normalised to a standard final concentration of $1.25 \mathrm{mg} / \mathrm{ml}$ following the addition of sample buffer, Laemmli $2 \mathrm{X}$ concentrate (Sigma), in a 1:1 ratio. Samples were boiled for 5 min prior to loading onto a $10 \%$ polyacrylamide gel. Following electrophoresis, proteins were blotted onto a Hybond-C Extra nitrocellulose membrane (Amersham Biosciences UK Ltd., Bucks, UK), blocked in $10 \%$ milk and subjected to specific antibody probing. Antibodies specific to HAI-1 were generated in-lab as

Table I. PCR primer sequences.

\begin{tabular}{lcc}
\hline Primer set & Sense & Antisense \\
\hline HAI-1 ribozyme 1 & ctgcagggccgagcgtgcacagaagccacaggcctgatgagtccgt & actagtcetcgccecggccggcatccetgcgtttcgtcctcacgga
\end{tabular}

(HA-1 RZ1f vs HAI-1 RZ1r)

HAI-1 probe

gattacgtatgectcgcatccaac

gatgatatctcagaggggecgggtggtgt

(HAI-1 SNABF vs HAI-1 EcoRVR) 


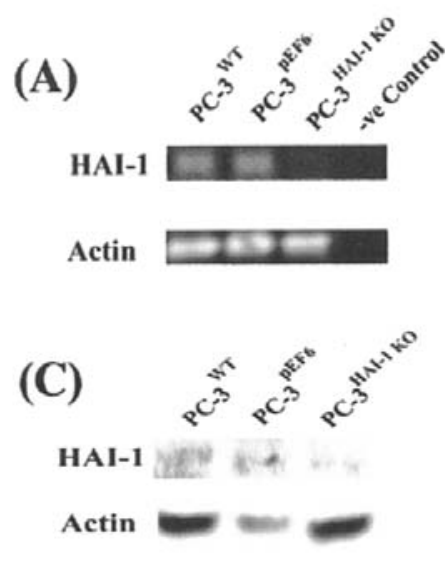

(E)

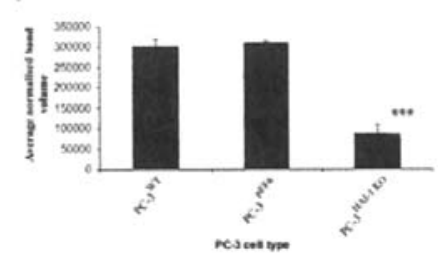

(B)

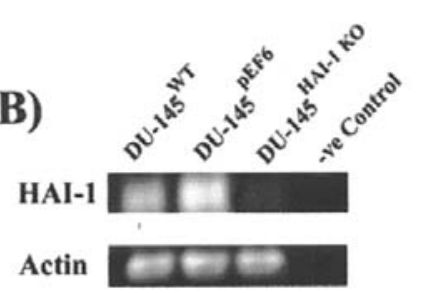

(D)

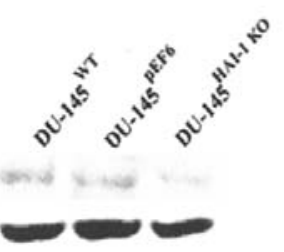

(F)

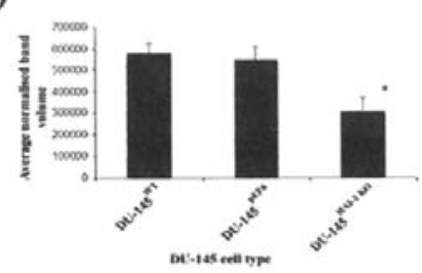

Figure 1. Confirmation of knockdown in HAI-1 expression in two prostate cancer cell lines. RT-PCR shows HAI-1 suppression at the mRNA level in the (A) PC-3 and (B) DU-145 cell lines. Suppression of HAI-1 expression at the protein level was also demonstrated using Western blotting in both the (C) PC-3 and (D) DU-145 cell lines. Histograms show normalised HAI-1 expression following band quantification and normalisation against 3 -actin expression in the (E) PC-3 and (F) DU-145 prostate cancer cell lines. In both cell lines a significant reduction in HAI-1 expression was observed in cells containing the HAI-1 ribozyme transgene, ${ }^{* * *} \mathrm{p} \leq 0.001$ and ${ }^{*} \mathrm{p} \leq 0.05$.

previously described (24). An anti-ß-actin antibody (Santa Cruz Biotechnology, Inc., CA, USA) at a concentration of 1:500 was used to probe for $\beta$-actin. Probing with primary antibody was followed by probing with peroxidaseconjugated anti-rabbit (HAI-1) or anti-goat (ß-actin) antibody (Sigma) at 1:1000 concentrations. Supersignal West Dura Extended Duration Substrate chemiluminescent system (Perbio Science UK Ltd., Cramlington, UK) was used to visualise protein bands which were detected using a CCD UVI Prochemi system (UVItec Ltd, Cambridge, UK). Using UVIsoft, UVIband software (UVItec Ltd) protein bands were quantified and normalised using the $\beta$-actin control run in order to allow semi-quantitative analysis of protein expression.

In vitro growth assay. Control and test cells were seeded into triplicate 96-well plates at a seeding density of 3,000 cells per well. Plates were incubated for 1,3 , and 5 days before being fixed in $4 \%$ formaldehyde $(\mathrm{v} / \mathrm{v})$, washed and stained with $0.5 \%(\mathrm{w} / \mathrm{v})$ crystal violet. Cell density and growth were then measured by extracting the crystal violet stain using $10 \%$ acetic acid (v/v) and measuring the absorbance on a Bio-Tek EL x 800 multiplate reader (Bio-Tek Instruments Inc., Winooski, VT, USA).

In vitro invasion assay. An in-vitro invasion assay was set up as previously described and modified by our group (25) to assess the invasive potential of the cells. In brief, 24-well plate inserts containing $8.0-\mu \mathrm{m}$ pores (Greiner Bio-One Ltd., Gloucestershire, UK) were each coated with $50 \mu \mathrm{g}$ of BD Matrigel Matrix Basement membrane (BD Biosciences, Oxford, UK), air dried and rehydrated before being seeded at a density of 15,000 cells per insert and incubated for $72 \mathrm{~h}$. Following incubation, cells that had invaded through the Matrigel layer and through the insert were fixed in $4 \%$ formaldehyde $(\mathrm{v} / \mathrm{v})$, rinsed and stained with $0.5 \%(\mathrm{w} / \mathrm{v})$ crystal violet before counting any cells that had invaded through in random fields under $\mathrm{x} 40$ objective magnification.

In vitro adhesion assay. The ability of the cells to adhere to an artificial Matrigel basement membrane was tested using an adhesion assay adapted from a previously described method (26). In brief, 45,000 cells were seeded into the wells of a 96-well plate which had been coated with $5 \mu \mathrm{g} /$ well of Matrigel. The cells were incubated for $45 \mathrm{~min}$ before being washed vigorously several times to remove unbound cells, fixed in $4 \%$ formaldehyde and stained with $0.5 \%$ (w/v) crystal violet. Random fields of adherent cells were then counted under x40 objective magnification.

In vitro motility assay. Cellular motility was assessed using a cytodex-2 bead motility assay as described previously (27). Briefly, $5 \times 10^{5}$ cells for each cell type were incubated in $10 \mathrm{ml}$ of growth medium containing $100 \mu 1$ of cytodex- 2 beads (GE Healthcare, Cardiff, UK) for $3.5 \mathrm{~h}$ to allow the cells to adhere to the beads. Following this, dead cells were removed with two washes of the beads in $5 \mathrm{ml}$ of growth medium. After the final wash, the beads were re-suspended in $1 \mathrm{ml}$ of growth medium before adding $200 \mu 1$ of this to a 24 -well plate containing a further $800 \mu \mathrm{l}$ of medium and were incubated overnight. Following overnight incubation, cells that had migrated from the cytodex- 2 beads and had adhered to the base of the well were fixed in $4 \%$ formaldehyde $(v / v)$ for 
(A)

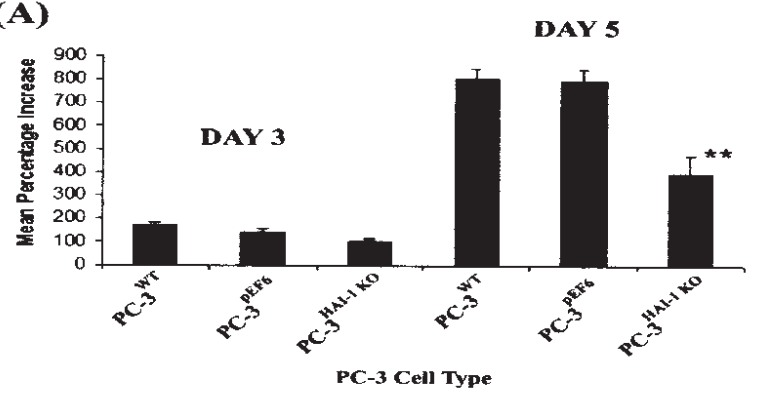

(B)

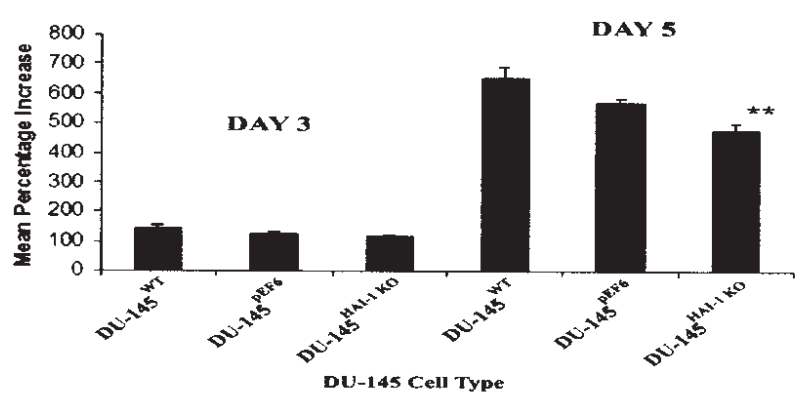

Figure 2. Growth assays demonstrating the effects of HAI-1 suppression on the (A) PC-3 and (B) the DU-145 cell lines. In both cases a significant reduction in growth capacity was seen following a 5-day incubation in cells containing the HAI- 1 ribozyme transgene (PC- $3^{\mathrm{HAI}-1 \mathrm{KO}}$ and DU- $\left.145^{\mathrm{HAI}-1 \mathrm{KO}}\right)$ compared to the respective controls (PC- $3^{\mathrm{PEF} 6}$ and DU-145 ${ }^{\mathrm{PEF} 6}$ ); ${ }^{* *} \mathrm{p} \leq 0.01$. No significant difference in growth was seen after 3 days.

5 min, stained with $0.5 \%$ crystal violet $(\mathrm{w} / \mathrm{v})$, and random fields were counted under $\mathrm{x} 40$ objective magnification following removal of cytodex -2 beads through extensive washing.

Statistical analysis. Experimental procedures were repeated independently at least three times. In all assays the cell lines showing reduced HAI-1 expression were compared to the pEF6 controls (cells containing closed pEF6 plasmid only) using a two-sample, t-tailed, t-test. The presented values represented the mean value \pm SEM, and values of $p \leq 0.05$ were considered statistically significant.

\section{Results}

Creation of PC-3 and DU-145 cell lines showing suppressed HAI-1 expression. The ability of the ribozyme transgene to knockout/knockdown HAI-1 expression in both the PC-3 and DU-145 cell lines was examined at both the messenger RNA and protein level (Fig. 1). RT-PCR was used to test for suppressed expression at the mRNA level and showed a large reduction of HAI-1 expression in both the PC-3 and DU-145 knockout cell types (PC-3 $3^{\mathrm{HAI}-1 \mathrm{KO}}$ and DU-145 $5^{\mathrm{HAI}-1 \mathrm{KO}}$ ) compared to the pEF6 control (PC-3 ${ }^{\mathrm{pEF} 6}$ and DU-145 ${ }^{\mathrm{pEF} 6}$ ) and wild-types (PC-3 ${ }^{\mathrm{WT}}$ and DU-145 ${ }^{\mathrm{WT}}$ ). Uniform gene expression between the cell types was confirmed using B-actin as a control. Similarly reduced expression of HAI-1 was also seen at the protein level using Western blotting. This reduction was found to be significant following protein band quantification using UVIband software (PC- $3^{\mathrm{pEF} 6}$ vs PC- $3^{\mathrm{HAI}-1 \mathrm{KO}}$, $\mathrm{p}=0.001$ and DU-145 ${ }^{\mathrm{pEF} 6}$ vs DU-145 ${ }^{\mathrm{HAI}-1 \mathrm{KO}}, \mathrm{p}=0.030$ ).
(A)

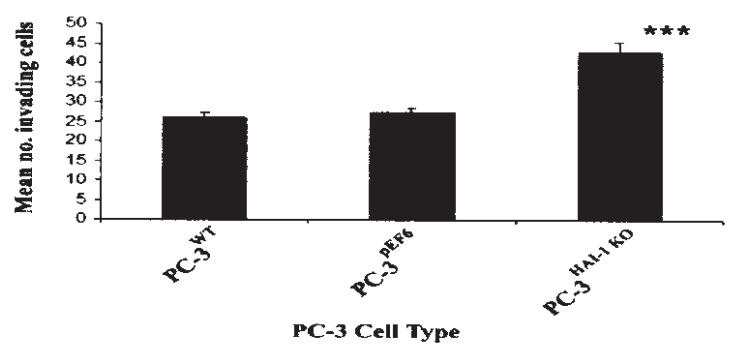

(B)

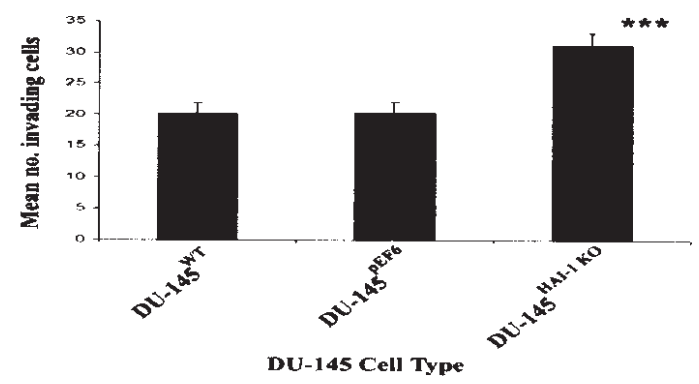

Figure 3. Matrigel invasion assay showing that an increased invasive capacity is associated with HAI-1 suppression in the (A) PC-3 and (B) DU-145 cell lines. Both PC- $3^{\mathrm{HAI}-1 \mathrm{KO}}$ and DU-145 $5^{\mathrm{HAI}-1 \mathrm{KO}}$ cells were found to be significantly more invasive than their corresponding pEF6 control cells; ${ }^{* * * *} \mathrm{p} \leq 0.001$.

Suppression of HAI-1 reduces the growth rate of $\mathrm{PC}-3$ and $D U-145$ cell lines. Notably, suppressing HAI-1 expression in the PC-3 and DU-145 cell lines was found to reduce the growth rate of both cell lines (Fig. 2) when compared to PC-3 or DU-145 cells containing the closed pEF6 plasmid alone (pEF6 controls). This reduction was found to be significant in both the PC-3 $(\mathrm{p}=0.01)$ and the DU-145 ( $\mathrm{p}=0.004)$ cell lines after a 5-day incubation period; no reduction in growth was seen after a 3-day incubation.

Suppressed HAI-1 levels promote invasiveness in PC-3 and $D U-145$ cells. Cells demonstrating reduced HAI-1 expression levels (PC-3 $3^{\mathrm{HAI}-1} \mathrm{KO}$ and DU-145 ${ }^{\mathrm{HAI}-1 \mathrm{KO}}$ ) were both found to have a greater ability to invade through an artificial Matrigel basement membrane (Fig. 3). This increased invasiveness was found to be highly significant when compared to the respective pEF6 control cell lines (PC- $3^{\mathrm{HAI}-1 \mathrm{KO}}$ vs PC- $3^{\mathrm{pEF}}$, $\mathrm{p}<0.001$ and DU-145 ${ }^{\mathrm{HAI}-1 \mathrm{KO}}$ vs DU-145 $\left.{ }^{\mathrm{pEF} 6}, \mathrm{p}<0.001\right)$. As these two cell lines produced very weak to negligible levels of HGF (data not shown), this increased invasion was likely due to the inhibition of matriptase-1, which has been demonstrated to play a dual role in invasion due to potential involvement in the uPA system (28), or through inhibition of other molecules important in invasion but not solely involved in the HGF pathway. Importantly, this result suggests that a decrease in HAI- 1 contributes to a more invasive cancer phenotype which strongly implies HAI-1 in the regulation and inhibition of cancer cell invasion, a key step in the process of metastasis.

Suppression of HAI-1 increases the ability of prostate cancer cells to adhere to an artificial basement membrane. 
(A)

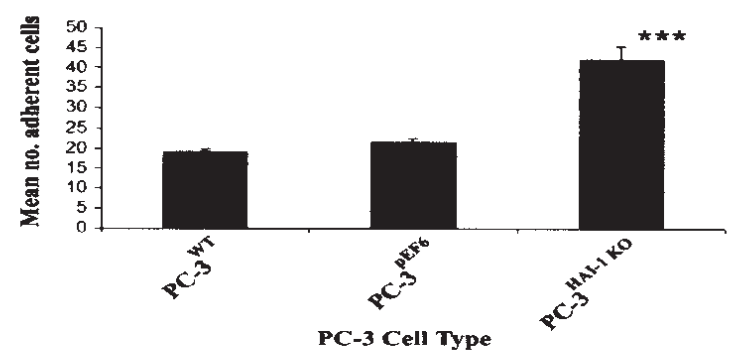

(B)

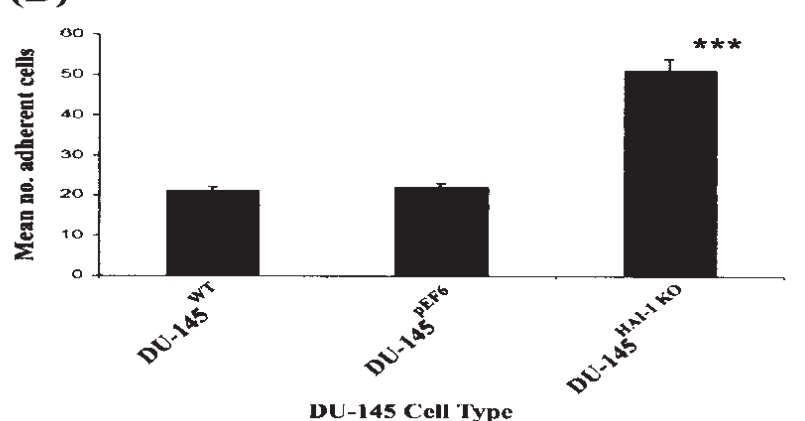

Figure 4. Matrigel adhesion assay showing the effects of HAI-1 suppression on the ability of cancer cells to adhere to an artificial Matrigel basement membrane. Both (A) PC-3 and (B) DU-145 cells containing the HAI-1 ribozyme transgene (PC-3 $3^{\mathrm{HAI}-1 \mathrm{KO}}$ and DU-145 ${ }^{\mathrm{HAI}-1 \mathrm{KO}}$ ) were found to have a significantly increased capacity to adhere to an artificial Matrigel basement membrane; ${ }^{* * *} \mathrm{p} \leq 0.001$.

Adhesion assays testing the ability of PC- $3^{\mathrm{HAI}-1}$ KO and DU$145^{\mathrm{HAI}-1 \mathrm{KO}}$ to adhere to an artificial Matrigel basement membrane showed an increase in adhesive ability in both of the HAI-1-suppressed cell types (Fig. 4). This increase was found to be highly statistically significant in both cases when compared to the pEF6 control cell types (PC-3 $3^{\mathrm{HAI}-1 \mathrm{KO}}$ vs PC $-3^{\text {pEF } 6}, \mathrm{p}<0.001$ and DU- $145^{\mathrm{HAI}-1 \mathrm{KO}} \mathrm{vs}$ DU $-145^{\mathrm{pEF} 6}$, $\mathrm{p}<0.001$ ) (following $\log 10$ transformation of DU-145 data sets to normalise data). Again, these data suggest that HAI-1 is involved in inhibiting the adherence of cancer cells to a basement membrane, another important stage in the metastatic process.

HAI-1 suppression increases motility of both the PC-3 and DU-145 cell lines. Suppression of HAI-1 in the PC-3 cell line was found to increase cellular motility (Fig. 5), the rate of cell dissemination from the cytodex-2 beads, and adherence to the tissue culture plate surface $\left(\mathrm{PC}-3^{\mathrm{HAI}-1} \mathrm{KO}\right.$ vs PC- $3^{\mathrm{pEF}}$, $\mathrm{p}<0.001)$. Similarly, suppression of HAI-1 in the DU-145 cells also significantly increased cellular motility and dissemination (DU-145 ${ }^{\mathrm{HAI}-1 \mathrm{KO}}$ vs DU-145 ${ }^{\mathrm{pEF} 6}, \mathrm{p}=0.005$ ). This suggests that HAI-1 is involved in the regulation of motility and the dissemination rate of prostate cancer cells.

\section{Discussion}

The HGF pathway is known to contribute to cancer aggressiveness due to its ability to promote angiogenesis, migration, cell morphogenesis, proliferation and its ability to enhance cell invasiveness (4-6). Hence as HAI-1 plays a role
(A)

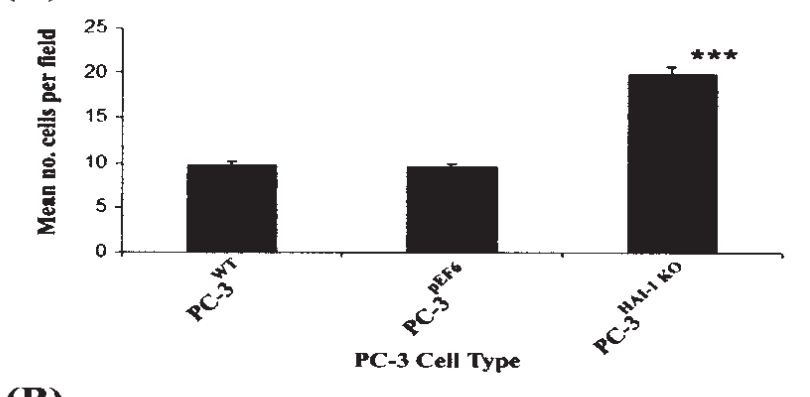

(B)

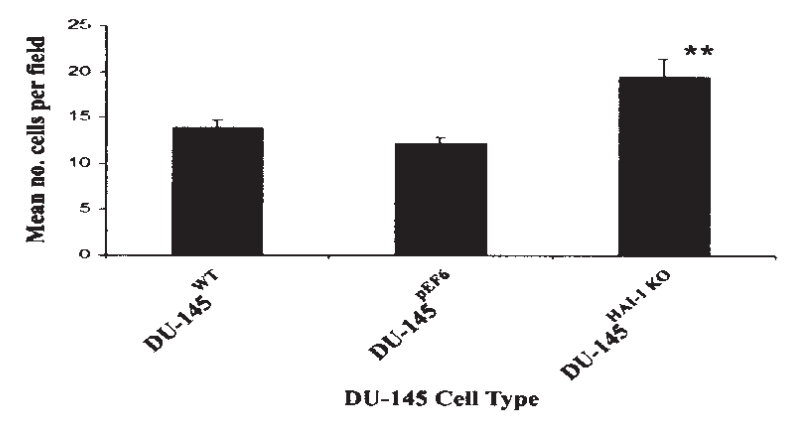

Figure 5. Cytodex-2 motility assay demonstrating the effects of suppressing the expression of the HAI-1 molecule in the (A) PC-3 and (B) DU-145 cell lines. In both cell lines a suppression of HAI-1 expression using the ribozyme transgene was associated with an increase in the motile nature of these cells; ${ }^{* * *} \mathrm{p} \leq 0.001$ and ${ }^{* *} \mathrm{p} \leq 0.01$.

in the regulation of this pathway through inhibition of key pro-HGF activators, it is highly likely that this molecule also contributes to regulating cancer aggressiveness associated with pro-HGF activation.

Disruption of the normal expression ratio between HAI-1 and associated proteases such as matriptase-1 or HGFA is believed to play a key role in cancer aggression, where more aggressive cancers have low levels of the inhibitor and higher protease levels. This disruption allows larger amounts of the protease to act in signalling pathways or matrix breakdown in an uninhibited manner. The disruption of this expression ratio was demonstrated in a study by Oberst et al in ovarian cancer. The study showed that matriptase- 1 expression was statistically more likely to occur in stage I/II ovarian tumours than in stage III/IV tumours, with HAI-1 expression similarly being more likely in stage I/II than stage III/IV tumours and that late-stage tumours expressing matriptase-1 were more likely to do so in the absence of HAI-1 (29). The importance of this expression ratio was further shown in a study by List et al where transgenic mice demonstrating a modest orthotopic overexpression of matriptase- 1 in their skin were shown to more frequently develop spontaneous squamous cell carcinoma and were found to be dramatically more susceptible to carcinogen-induced tumour formation. Crossing of the matriptase- 1 overexpressing line with an HAI-1 overexpressing transgenic line resulted in double transgenic mice showing overexpression of both matriptase-1 and HAI-1. In these mice the overexpression of HAI-1, in addition to matriptase-1, completely negated the oncogenic effects of matriptase-1 (30). Disruption of this expression ratio has also been demonstrated in colon cancer, where a 
significantly different matriptase-1/HAI-1 mRNA ratio was seen between both adenomas and carcinomas and the corresponding normal tissue. Dysregulation of the mRNA expression ratio was shown to occur during early carcinogenesis (31).

Throughout this study we have shown that targeting of HAI-1 expression using a ribozyme transgene resulted in prostate cancer cells that were more invasive, more motile and more adhesive, though strangely these cells also demonstrated a reduced growth capacity over a period of five days. These results are largely consistent with similar studies conducted in our laboratories targeting HAI-1 expression in MDA-MB-231 breast cancer cells, where suppression of HAI-1 also resulted in a more invasive and motile phenotype, though these cells were found to have increased proliferative rates. Generation of fibroblast MRC5 cells where HAI-1 expression was induced resulted in a reduced capacity of these cells to produce bio-active HGF and to promote breast cancer cell invasion in a co-culture system. Similar trends were also seen when HAI-1 recombinant protein was added to a co-culture system (32). Taken together, these data suggest the involvement of HAI-1 in the regulation of cancer development and progression, linking it to several key traits associated with cancer metastasis. In these two studies, altering the expression of HAI-1 in breast and prostate cancer cells was associated with a change in aggressiveness of the cancer cells. This is consistent with the current theory that the expression ratio between key proteases such as matriptase-1 and HGFA and HAI-1 is a key factor in regulating cancer progression, and that disruption of this expression ratio is important in determining the aggressiveness of the cancer.

In conclusion, suppression of HAI- 1 results in a more aggressive, invasive cancer cell phenotype. This increased aggression is most likely through a disruption in the levels of proteases and associated inhibitors in the system allowing greater activation of key growth factors such as HGF. However, though HGF activation undoubtedly contributes to an increased aggression in some systems, it is unlikely that it is the only factor involved as the PC-3 cells used in this study exhibited no HGF expression at the PCR level (data not shown). This study suggests that HAI-1 plays an important role in prostate cancer development, progression and metastasis, and that it is capable of regulating pathways other than HGF activation through its regulation of serine proteases such as matriptase-1 which has been shown to be involved in the uPA pathway and PAR-2 signalling $(13,33)$.

\section{Acknowledgements}

We would like to thank Cancer Research Wales for supporting this study. The authors are indebted to Dr Gaynor Davies (1967-2006) for her invaluable assistance in the study.

\section{References}

1. Michalopoulos G, Houck KA, Dolan ML and Luetteke NC: Control of hepatocyte replication by two serum factors. Cancer Res 44: 4414-4419, 1984.

2. Nakamura T, Nawa $K$ and Ichihara A: Partial purification and characterization of hepatocyte growth factor from serum of hepatectomized rats. Biochem Biophys Res Commun 122: 1450-1459, 1984.
3. Russell WE, McGowan JA and Bucher NL: Partial characterization of a hepatocyte growth factor from rat platelets. J Cell Physiol 119: 183-192, 1984.

4. Grant DS, Kleinman HK, Goldberg ID, Bhargava MM, Nickoloff BJ, Kinsella JL, Polverini P and Rosen EM: Scatter factor induces blood vessel formation in vivo. Proc Natl Acad Sci USA 90: 1937-1941, 1993.

5. Sugawara J, Fukaya T, Murakami T, Yoshida H and Yajima A: Hepatocyte growth factor stimulates proliferation, migration, and lumen formation of human endometrial epithelial cells in vitro. Biol Reprod 57: 936-942, 1997.

6. Weidner KM, Behrens J, Vandekerckhove J and Birchmeier W: Scatter factor: molecular characteristics and effect on the invasiveness of epithelial cells. J Cell Biol 111: 2097-2108, 1990.

7. Jiang WG, Grimshaw D, Lane J, Martin TA, Abounder R, Laterra J and Mansel RE: Hammerhead ribozyme suppresses expression of hepatocyte growth factor/scatter factor receptor cMET and reduces migration and invasiveness of breast cancer cells. Clin Cancer Res 7: 2555-2562, 2001.

8. Martin TA, Parr C, Davies G, Watkins G, Lane J, Matsumoto K, Nakamura T, Mansel RE and Jiang WG: Growth and angiogenesis of human breast cancer in a nude mouse tumour model is reduced by NK4, a HGF/SF antagonist. Carcinogenesis 24: 1317-1323, 2003.

9. Naka D, Ishii T, Yoshiyama Y, Miyazawa K, Hara H, Hisida T and Kitamura N: Activation of hepatocyte growth factor by proteolytic conversion of a single chain form to a heterodimer. $\mathbf{J}$ Biol Chem 267: 20114-20119, 1992.

10. Gak E, Taylor WG, Chan AML and Rubin JS: Processing of hepatocyte growth factor to the heterodimeric form is required for biological activity. FEBS Lett 311: 17-21, 1992.

11. Miyazawa K, Shimomura T and Kitamura N: Activation of hepatocyte growth factor in the injured tissues is mediated by hepatocyte growth factor activator. J Biol Chem 271: 3615-3618, 1996.

12. Shimomura T, Kondo J, Ochiai M, Naka D, Miyazawa K, Morimoto Y and Kitamura N: Activation of the zymogen of hepatocyte growth factor activator by thrombin. J Biol Chem 268: 22927-22932, 1993.

13. Lee SL, Dickson RB and Lin CY: Activation of hepatocyte growth factor and urokinase/plasminogen activator by matriptase, an epithelial membrane serine protease. J Biol Chem 275: 36720-36725, 2000.

14. Shimomura T, Denda K, Kitamura A, Kawaguchi T, Kito M, Kondo J, Kagaya S, Qin L, Takata H, Miyazawa K and Kitamura N: Hepatocyte growth factor activator inhibitor, a novel Kunitz-type serine protease inhibitor. J Biol Chem 272: 6370-6376, 1997.

15. Kawaguchi T, Qin L, Shimomura T, Kondo J, Matsumoto K, Denda $\mathrm{K}$ and Kitamura N: Purification and cloning of hepatocyte growth factor activator inhibitor type 2, a Kunitz-type serine protease inhibitor. J Biol Chem 272: 27558-27564, 1997.

16. Itoh H, Yamauchi M, Kataoka H, Hamasuna R, Kitamura N and Koono M: Genomic structure and chromosomal localization of the human hepatocyte growth factor activator inhibitor type 1 and 2 genes. Eur J Biochem 267: 3351-3359, 2000.

17. Herter S, Piper DE, Aaron W, Gabriele T, Cutler G, Cao P, Bhatt AS, Choe Y, Craik CS, Walker N, Meininger D, Hoey T and Austin RJ: Hepatocyte growth factor is a preferred in vitro substrate for human hepsin, a membrane-anchored serine protease implicated in prostate and ovarian cancers. Biochem $\mathbf{J}$ 390: 125-136, 2005.

18. Kirchofer D, Peek M, Li W, Stamos J, Eigenbrot C, Kadkhodayan S, Elliott JM, Corpuz RT, Lazarus RA and Moran P: Tissue expression, protease specificity, and Kunitz domain functions of hepatocyte growth factor activator inhibitor-1B (HAI-1B), a new splice variant of HAI-1. J Biol Chem 278: 36341-36349, 2003.

19. Oberst MD, Williams CA, Dickson RB, Johnson MD and Lin CY: The activation of matriptase requires its noncatalytic domains, serine protease domain, and its cognate inhibitor. J Biol Chem 278: 26773-26779, 2003.

20. Kataoka H, Suganuma T, Shimomura T, Itoh H, Kitamura N, Nabeshima K and Koono M: Distribution of hepatocyte growth factor activator inhibitor type 1 (HAI-1) in human tissues: cellular surface localization of HAI-1 in simple columnar epithelium and its modulated expression in injured and regenerative tissues. J Histochem Cytochem 47: 673-682, 1999. 
21. Itoh H, Kataoka H, Tomita M, Hamasuna R, Nawa Y, Kitamura N and Koono M: Upregulation of HGF activator inhibitor type 1 but not type 2 along with regeneration of intestinal mucosa. Am J Physiol Gastrointest Liver Physiol 278: G635-G643, 2000.

22. Jiang WG, Davies G and Fodstad O: Com-1/P8 in oestrogen regulated growth of breast cancer cells, the ER- $\beta$ connection. Biochem Biophys Res Commun 330: 253-262, 2005.

23. Jiang WG, Davies G, Martin TA, Parr C, Watkins G, Mason MD, Mokbel K and Mansel RE: Targeting matrilysin and its impact on tumour growth in vivo: the potential implications in breast cancer therapy. Clin Cancer Res 11: 6012-6019, 2005.

24. Parr C, Watkins G, Mansel RE and Jiang WG: The hepatocyte growth factor regulatory factors in human breast cancer. Clin Cancer Res 10: 202-211, 2004.

25. Jiang WG, Hiscox S, Hallett MB, Horrobin DF, Mansel RE and Puntis MCA: Regulation of the expression of E-cadherin on human cancer cells by gamma linolenic acid. Cancer Res 55: 5043-5048, 1995

26. Jiang WG, Hiscox S, Hallett MB, Horrobin DF, Scott C and Puntis MCA: Inhibition of invasion and motility of human colon cancer cells by gamma linolenic acid. Br J Cancer 71: 744-752, 1995.

27. Jiang WG, Hiscox S, Singhrao SK, Nakamura T, Puntis MCA and Hallet MB: Inhibition of $\mathrm{HGF} / \mathrm{SF}$-induced membrane ruffling and cell motility by transient elevation of cytosolic free $\mathrm{Ca}^{2+}$. Exp Cell Res 220: 424-433, 1995.
28. Förbs D, Thiel S, Stella MC, Stürzebecher A, Schweinitz A, Steinmetzer T, Stürzebecher J and Uhland $\mathrm{K}$ : In vitro inhibition of matriptase prevents invasive growth of cell lines of prostate and colon carcinomas. Int J Oncol 27: 1061-1070, 2005.

29. Oberst MD, Johnson MD, Dickson RB, Lin CY, Singh B, Stewart M, Williams A, al-Nafussi A, Smyth HF, Gabra H and Stellar GC: Expression of the serine protease matriptase and its inhibitor HAI-1 in epithelial ovarian cancer: correlation with clinical outcome and tumour clinicopathological parameters. Clin Cancer Res 8: 1101-1107, 2002.

30. List K, Szabo R, Molinolo A, Sriuranpong V, Redeye V, Murdock T, Burke B, Nielsen BS, Gutkind JS and Bugge TH: Deregulated matriptase causes ras-independent multistage carcinogenesis and promotes ras-mediated malignant transformation. Genes Dev 19: 1934-1950, 2005.

31. Vogel LK, Saebo M, Skjelbred CF, Abell K, Pedersen ED, Vogel U and Kure EH: The ratio of Matriptase/HAI-1 mRNA is higher in colorectal cancer adenomas and carcinomas than corresponding tissue from control individuals. BMC Cancer 6: $176,2006$.

32. Parr C and Jiang WG: Hepatocyte growth factor activation inhibitors (HAI-1 and HAI-2) regulate HGF-induced invasion of human breast cancer cells. Int J Cancer 119: 1176-1183, 2006.

33. Takeuchi T, Harris JL, Huang W, Yan KW, Coughlin SR and Craik CS: Cellular localization of membrane-type serine protease 1 and identification of protease-activated receptor-2 and single-chain urokinase-type plasminogen activator as substrates. J Biol Chem 275: 26333-26342, 2000. 